\title{
Expression of the Lactate Dehydrogenase Gene from Eptatretus okinoseanus in Escherichia coli
}

\author{
Yoshikazu Nishiguchi, ${ }^{1}$ Akira Uchida, ${ }^{2}$ Noriko Oshima, ${ }^{2}$ and Mitsumasa Okada ${ }^{2}$ \\ ${ }^{1}$ Faculty of Pharmaceutical Sciences, Toho University, Chiba 2748510, Japan \\ ${ }^{2}$ Faculty of Science, Toho University, Chiba 2748510, Japan \\ Correspondence should be addressed to Yoshikazu Nishiguchi, guchi@phar.toho-u.ac.jp
}

Received 31 March 2011; Accepted 3 May 2011

Academic Editors: V. Almeida-Val and A. Ramirez-Bautista

Copyright (@ 2011 Yoshikazu Nishiguchi et al. This is an open access article distributed under the Creative Commons Attribution License, which permits unrestricted use, distribution, and reproduction in any medium, provided the original work is properly cited.

Amplified Eptatretus okinoseanus cDNA was digested with NdeI and EcoRI, cloned into pCold trigger factor (TF), and transformed with Escherichia coli strain BL 21 in which a csp A promoter was introduced to inhibit the expression of foreign peptides. Recombinant lactate dehydrogenase (LDH) was obtained in the soluble fraction after sonication of the cells. The protein was digested by HRC 3C protease, thrombin, and factor Xa. The specific activity of TF-tagged protein and tagless protein were $0.646 \times 10^{6} \mathrm{mIU} / \mathrm{mg}$ and $3.56 \times 10^{6} \mathrm{mIU} / \mathrm{mg}$, respectively. The deletion of the TF tag enhanced the activity compared with the native protein to $13.4 \times 10^{6} \mathrm{mIU} / \mathrm{mg}$, showing that this expression method is effective for the mass production of the protein to allow further study of the structure of LDH.

\section{Introduction}

Lactate dehydrogenase (L-lactate: NAD oxidoreductase, EC 1.1.1.27; LDH) is a key enzyme in the glycolytic reaction cascade due to its metabolic significance in catalyzing the terminating step. The physicochemical properties of the enzyme have been described in detail [1-5]. In most vertebrates, the $\mathrm{LDH}$ molecule forms a tetrameric structure [6] and two separate loci that encode the A and B subunits constructing five tetrameric isozymes have been identified [7]. There has been great interest in LDH isozymes since their occurrence varies during evolution [8], fetal development [9], and cancer development [10]. We previously reported the enzymatic properties of LDHs of several hagfish species, which are prototype fish living at a wide range of depths [11-15]. The skeletal muscle of two hagfish, Eptatretus okinoseanus and Paramyxine atami, and of a lamprey, Entosphenus japonicus, has the $\mathrm{A}_{4}$ isozyme whereas the $\mathrm{B}_{4}$ isozyme was expressed in the heart of the hagfish E. okinoseanus and P. atami, but not in E. japonicus. No heteroisozymes were detected in Cyclostomata [13]. In 2004, Johns and Somero [16] proposed the heat-tolerant structure of Pomacentridae LDH, and in 2008 Brindley et al. [17] reported the pressuretolerant structure of Gadidae LDH-B and proposed 21 amino acid residues responsible for it. Recently, we have sequenced LDH-A genes from three hagfish species [13], examined their activities under high pressure, proposed seven amino acid residues responsible for their pressure tolerance $[15,18]$, and found that the dissociation of tetramers caused the inactivation of Eptatretus burgeri LDH under high pressure [19]. This study aimed to determine a method for the effective expression of the LDH gene in Escherichia coli to obtain sufficient proteins to investigate the pressure-resistant structure using X-ray analysis.

Many studies on the expression of LDH in E. coli have been reported [20,21], but almost all were on fusion proteins or proteins with relatively large amino acid residues with properties different from the native one in their threedimensional structures and enzyme activities. In this study, we examined the optimum conditions to remove the tag of fused proteins. We are currently performing site-directed mutagenesis of the predicted amino acids and will express those mutagenic LDHs in E. coli using this method to examine the mechanism of pressure tolerance. 


\section{Materials and Methods}

Eptatretus okinoseanus was collected from Suruga Bay off Shizuoka, Japan. The sampling location was $34-35^{\prime}$ N, 138$139^{\prime} \mathrm{E}$ at depths of approximately $700-1000 \mathrm{~m}$ (ambient seawater temperature $5-8^{\circ} \mathrm{C}$ ). Skeletal muscles were washed with phosphate-buffered saline (PBS; $8.1 \mathrm{mM} \mathrm{Na}_{2} \mathrm{HPO}_{4}$, $1.5 \mathrm{mM} \mathrm{KH} \mathrm{KH}_{2} \mathrm{PO}_{4}, 2.7 \mathrm{mM} \mathrm{KCl}, 137 \mathrm{mM} \mathrm{NaCl}$ ) pretreated with diethylpyrocarbonate to remove RNase and immediately frozen at $-80^{\circ} \mathrm{C}$.

Messenger RNAs (mRNAs) were isolated from homogenates of skeletal muscle following the method of Loening [22]. Total cDNA was subjected to PCR with the following two primers: F1, 5' -TCGAAGGTAGGCATATGTCGACCGTGCGGGAACGT-3'; R1, 5' -CGACAAGCTTGAATTCTTACAGTTTCAGGTCCTTC-3'. A typical thermal cycling profile consisted of 30 cycles of the following three steps: denaturation at $98^{\circ} \mathrm{C}$ for $10 \mathrm{~s}$; annealing at $55^{\circ} \mathrm{C}$ for $10 \mathrm{~s}$; extension at $72^{\circ} \mathrm{C}$ for $45 \mathrm{~s}$. The cycling steps were preceded by 2 -minute denaturation at $94^{\circ} \mathrm{C}$ followed by 7 -minute extension at $72^{\circ} \mathrm{C}$. The amplified cDNA was digested with NdeI and EcoRI and cloned into pCold trigger factor (TF; Takara Bio Inc., Tokyo, Japan) into which a csp A promoter, active only at low temperature, was inserted. The E. okinoseanus LDH-A open reading frame (ORF) was inserted asymmetrically into the NdeI and EcoRI sites of the pCold TF vector. The sequence of the resulting plasmid was confirmed using an Applied Biosystems 3730 Genetic Analyzer (Applied Biosystems, Tokyo, Japan).

The plasmid was transformed with E. coli strain BL 21 . Luria-Bertani broth with $100 \mu \mathrm{g} / \mathrm{mL}$ ampicillin was inoculated into the overnight culture of the transformed E. coli. When the absorbance at $600 \mathrm{~nm}$ reached a value of $0.5, \beta$ $D$-thiogalactopyranoside was added at a final concentration of $1 \mathrm{mM}$, and the cultures were allowed to stand at $15^{\circ} \mathrm{C}$ for $24 \mathrm{~h}$. The bacteria were harvested by centrifugation at $5,000 \times \mathrm{g}$ for $15 \mathrm{~min}$. Cell pellets were resuspended and disrupted using a sonicator in PBS. After centrifugation at $12,000 \times \mathrm{g}$ for $20 \mathrm{~min}$, the supernatant was applied to a cobalt-based immobilized method affinity chromatography resin column (IMAC, Clontech Laboratories Inc., Mountain View, CA, USA). After washing the column with $50 \mathrm{mM}$ $\mathrm{NaH}_{2} \mathrm{PO}_{4}$ (pH 8.0) containing $20 \mathrm{mM}$ imidazole, tagged $\mathrm{LDH}$ was eluted with $50 \mathrm{mM} \mathrm{NaH}_{2} \mathrm{PO}_{4}$ (pH 8.0) containing $300 \mathrm{mM}$ imidazole. The purified tagged LDH was confirmed with SDS-PAGE. The LDH tagged with the TF, a 48$\mathrm{kDa}$ protein, was cleaved with three restriction enzymes, HRC $3 \mathrm{C}$ protease, thrombin, and factor Xa (Figure 1). The cleaved samples were subjected to electrophoresis using polyacrylamide gel. After electrophoresis, the gel was stained with EzStain Reverse (ATTO Corporation Tokyo, Japan), which did not inhibit LDH activity in contrast to Coomassie Brilliant Blue. The bands of LDH were cut from the gel, and LDH was extracted from the gel using ATTOPREP MF (ATTO Corporation).

LDH activity was determined in an assay medium ( $0.83 \mathrm{mM}$ pyruvate, $0.13 \mathrm{mM}$ NADH, $0.1 \mathrm{M}$ phosphate buffer, $\mathrm{pH} 6.2$ ) at $30^{\circ} \mathrm{C}$. One unit of activity was defined as $1 \mu \mathrm{mol}$ of product $(\mathrm{NAD}+)$ formed from the reduction of pyruvate to lactate per minute per milligram of protein.

\section{Results and Discussion}

Figure 1 shows the genetic engineering scheme for the construction of the E. okinoseanus LDH-A ORF and pCold TF vector. The recombinant DNA has the csp A promoter to upregulate the target protein production at lower incubation temperatures $\left(15^{\circ} \mathrm{C}\right)$. At $15^{\circ} \mathrm{C}$, the expression of other cellular proteins is inhibited. The TF causes the expressed protein to become soluble in E. coli. The disruption of the E. coli cell wall to liberate active protein was attempted using two methods. One was disruption with zwitterionic detergent (BugBuster Protein Extraction Reagent; Takara Bio Inc., Tokyo, Japan). In this treatment, all LDH activity was lost. The other method was sonication (100 W, $10 \mathrm{~min})$, after which LDH activity remained.

Figure 2 shows the results of SDS-PAGE of the soluble fraction (lane S), insoluble fraction (lane I), and tagged $\mathrm{LDH}$ in the soluble fraction purified with IMAC (lane P). Almost all of the expression of recombinant protein occurred in the soluble fraction, with insignificant expression in the insoluble fraction. There were only small amounts of foreign proteins (lane T), showing that csp A effectively inhibited the expression of the original E. coli proteins. Since the TF tag decreases the activity of recombinant $\mathrm{LDH}$, we attempted to remove the tag. Column chromatography resulted in significant purification of the recombinant LDH. Figure 1 shows the cleavage sites of the three proteases. HRV 3C protease retained 17 amino acid residues, thrombin retained eight, and factor Xa retained one, indicating that the third protease was the optimal treatment to obtain nearly natural LDH. Figure 3 shows the digestion of tagged LDH by the three proteases. $\mathrm{LDH}$ was treated with $0.1-5 \mathrm{U}$ of HRV $3 \mathrm{C}$ protease at $4^{\circ} \mathrm{C}$ for $16 \mathrm{~h}$, and it was found that $5 \mathrm{U}$ was the optimal dose (lanes 2-4). The results of reatment with thrombin at $25^{\circ} \mathrm{C}$ for $16 \mathrm{~h}$ showed that $5 \mathrm{U}$ was optimal (lanes 5-7). After digestion by factor $\mathrm{Xa} 0.1-5 \mathrm{U}$ at $25^{\circ} \mathrm{C}$ for $16 \mathrm{~h}$, no clear peptide bands were observed (lanes 8-10), and the reason for this is illustrated in Figure 4. Isolation of the $\mathrm{LDH}$ cleaved by HRV 3C protease was performed using IMAC. LDH passed through the column, although approximately $20 \%$ of the TF tag also passed through the column and thus purification was not achieved. Thrombindigested LDH was also not purified, since thrombin passed through the column with LDH (data not shown). Digestion of tagged LDH by factor Xa was performed using a modified method to avoid salting-out under the cleavage conditions shown in Figure 3. The reaction mixture was diluted 10-fold with distilled water. Figure 4 shows the results of digestion by $0.1-5 \mathrm{U}$ of factor $\mathrm{Xa}$ in the modified method at $20^{\circ} \mathrm{C}$ for $16 \mathrm{~h}$ (lanes 2-4). A band of digested LDH was identified after treatment with $1 \mathrm{U}$ of factor Xa (lane 3). Factor Xadigested LDH was subjected to electrophoresis with gradient PAGE and stained with Coomassie Brilliant Blue (Figure 5). Those bands were broad since SDS was absent. Recombinant LDH (lane 2) was isolated around the same migrating 


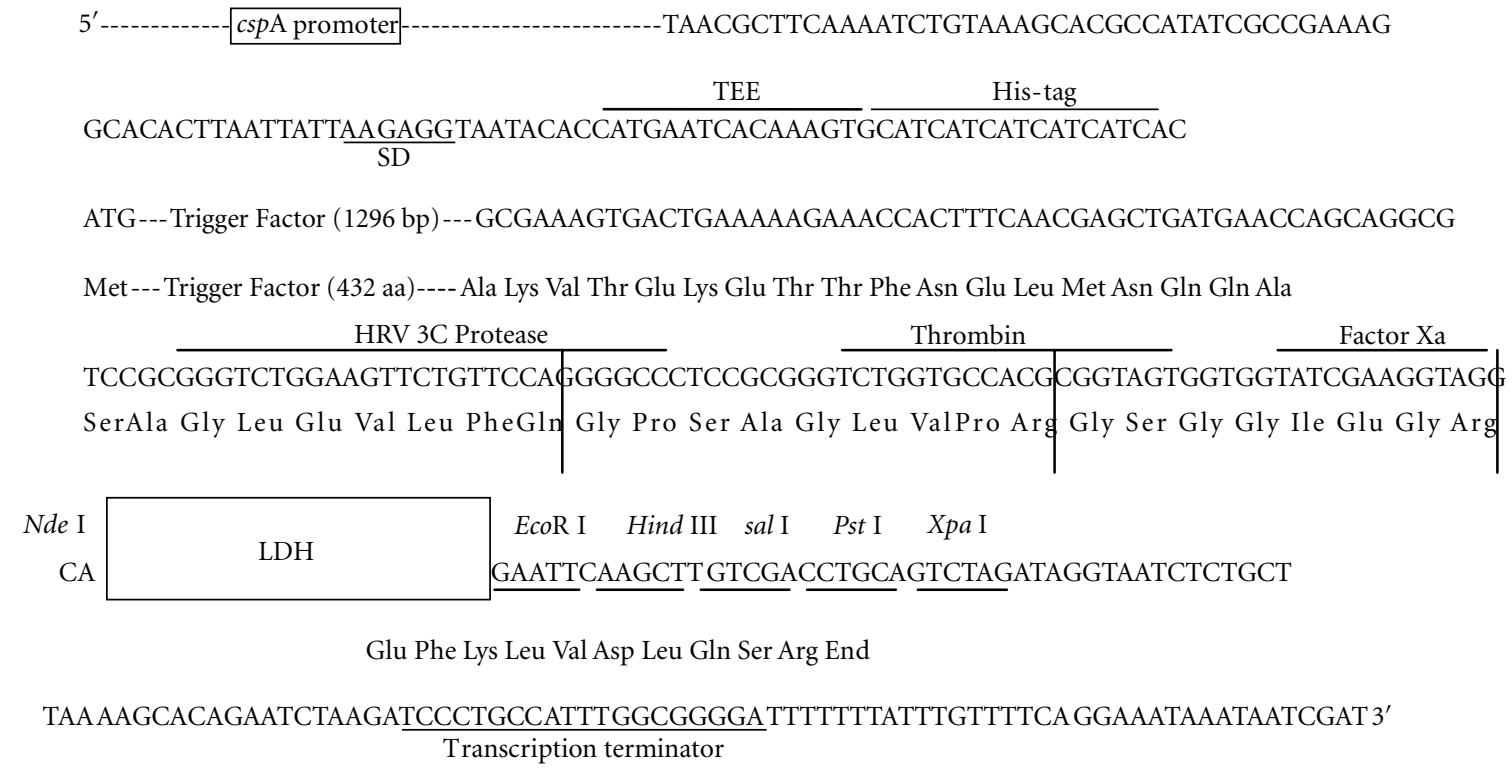

FIgURE 1: Genetic engineering scheme for construction of E. okinoseanus LDH-A open reading frame (ORF) and pCold TF vector. The E. okinoseanus LDH-A ORF was inserted asymmetrically into the NdeI and EcoRI sites of the pCold TF vector into which a csp A promoter. The pCold TF vector with LDH includes a translation enhancing element (TEE), a His-tag sequence, and three sites cleaved by proteases (HRV 3C protease, Thrombin, and Factor Xa).

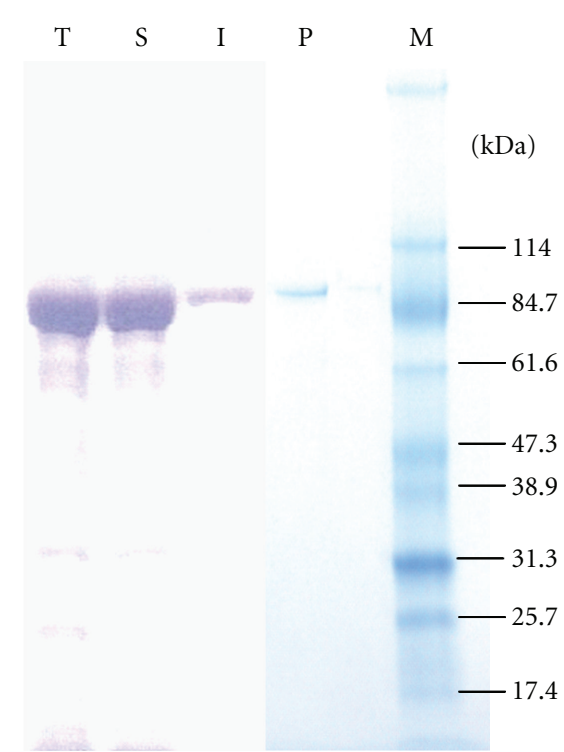

Figure 2: SDS-PAGE of purified LDH-A fusion protein. T: total fraction, S: soluble fraction, I: insoluble fraction, P: purified LDH with TF-tag, M: molecular size markers.

position as native LDH (lane 1) and extracted from the gel. After electrophoresis, the gel was stained with EzStain Reverse (ATTO Corporation), which did not inhibit LDH activity in contrast to Coomassie Brilliant Blue. The bands of $\mathrm{LDH}$ were cut from the gel, and LDH was extracted from the gel with ATTOPREP MF (ATTO Corporation). Table 1 shows that the activity of recombinant LDH without the TF tag was 5-fold greater than that with the TF tag. These

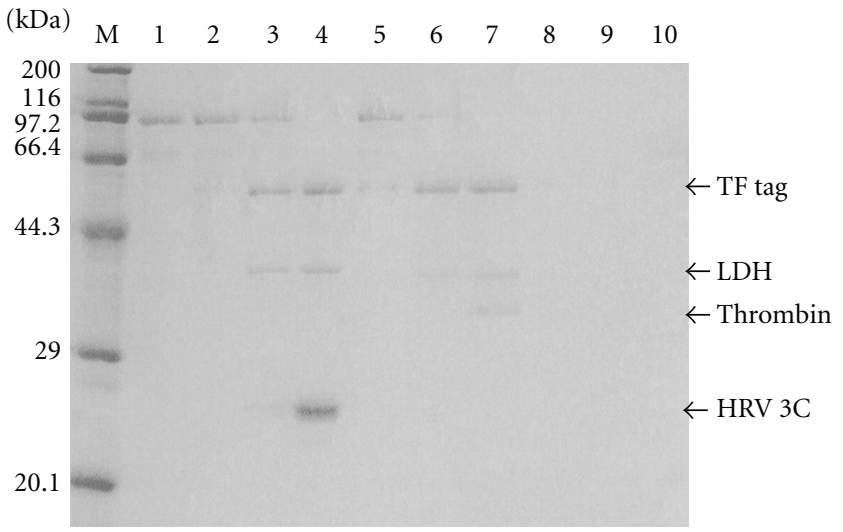

FIGURE 3: Digestion by three proteases, HRV 3C protease, thrombin, and factor Xa. M: molecular size markers, 1: purified LDH with TF tag, 2: digestion by $0.1 \mathrm{U}$ of HRV 3C, 3: digestion by $1 \mathrm{U}$ of HRV 3C, 4: digestion by $5 \mathrm{U}$ of HRV 3C, 5 : digestion by $0.1 \mathrm{U}$ of thrombin, 6: digestion by $1 \mathrm{U}$ of thrombin, 7: digestion by $5 \mathrm{U}$ of thrombin, 8: digestion by $0.1 \mathrm{U}$ of factor $\mathrm{Xa}$, 9: digestion by $1 \mathrm{U}$ of factor Xa, 10: digestion by $5 \mathrm{U}$ of factor Xa.

results confirm that the TF tag disrupts the combination of monomers into tetramers in LDH. Some reports described the properties of LDH expressed with a tag [20,21]. However, there are few reports comparing the enzymatic properties of expressed and native LDH, except for the report of Johns and Somero [16], who found that the $\mathrm{Km}$ values for pyruvate at $20^{\circ} \mathrm{C}$ were nearly equivalent in native $\mathrm{LDH}-\mathrm{A}$ from Chromis punctipinnis and in the recombinant form. Determining the effects of a tag in expressed LDH is important for analyzing its enzymatic properties. To the best of our knowledge, this 


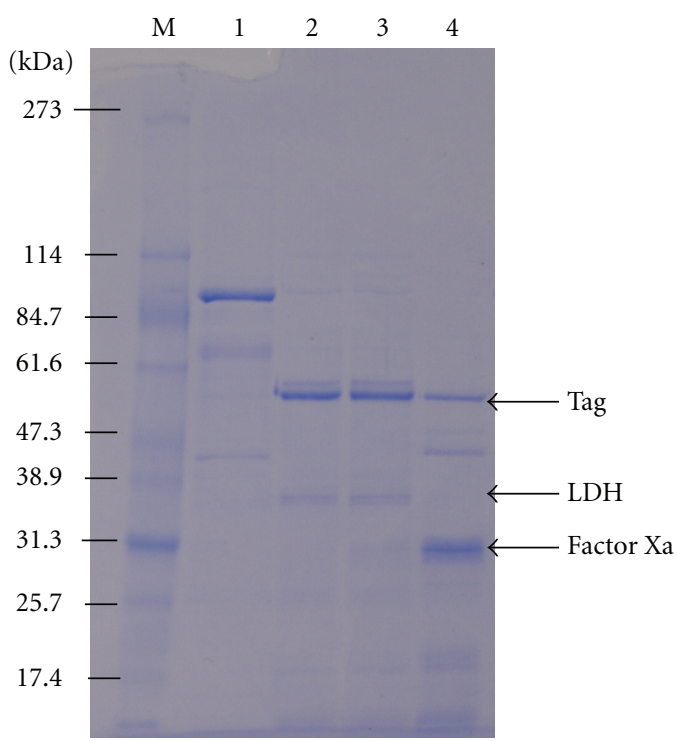

Figure 4: Digestion by factor Xa using the modified method. M: molecular size markers, 1: TF-tagged $\mathrm{LDH}, 2$ : digestion by $0.1 \mathrm{U}$, 3: digestion by $1 \mathrm{U}, 4$ : digestion by $5 \mathrm{U}$. To avoid salting-out under the cleavage conditions shown in Figure 3, the reaction solution was diluted by 10 -fold with distilled water.

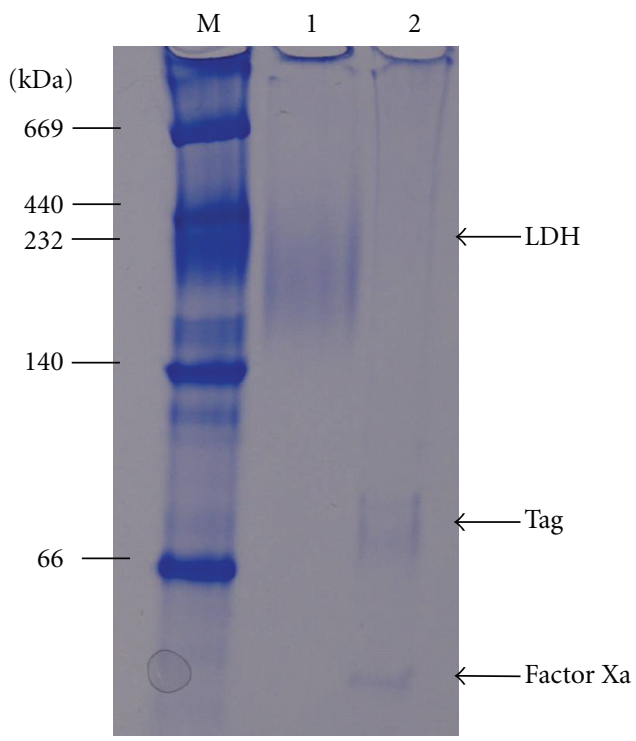

FIGURE 5: Gradient (5-20\%) polyacrylamide gel electrophoresis. The tagged $\mathrm{LDH}$ was digested by factor $\mathrm{Xa}$ and subjected to electrophoresis. M: molecular size markers, 1: LDH purified from muscle, 2: fusion protein digested by $1 \mathrm{U}$ of factor Xa.

is the first report comparing the activities of expressed LDH with and without a tag and those of the native enzyme.

We are currently performing site-directed mutagenesis of LDH and expressing it in E. coli. The mechanism of adaptation of LDHs from deep-sea hagfish to high pressure will be clarified at the amino acid sequence level in our ongoing experiments.
TABLe 1: Specific activities of purified LDH from muscle, tagged LDH, and tag-less LDH.

\begin{tabular}{lc}
\hline & Specific activity $\left(\times 10^{6} \mathrm{~m} \mathrm{IU} / \mathrm{mg}\right)$ \\
\hline Purified LDH from muscle & 13.4 \\
LDH expressed in E. coli & \\
$\quad$ with TF-tag & 0.646 \\
$\quad$ without TF-tag & 3.56 \\
\hline
\end{tabular}

\section{References}

[1] O. Warburg and W. Christian, "Pyridin, der wasserstoffubertragende bestandteil von garungsfermenten," Biochemische Zeitschrift, vol. 287, pp. 291-328, 1936.

[2] F. B. Straub, "Crystalline lactic dehydrogenase from heart muscle," Biochemistry Journals, vol. 34, no. 4, pp. 483-486, 1940.

[3] F. A. Loewus and H. A. Stafford, "The enzymatic transfer of hydrogen by glyceric and lactic dehydrogenases," The Journal of Biological Chemistry, vol. 235, pp. 3317-3321, 1960.

[4] D. Dennis and N. O. Kaplan, "D- and L-lactic acid dehydrogenases in Lactobacillus plantarum," The Journal of Biological Chemistry, vol. 235, pp. 810-818, 1960.

[5] J. F. Biellmann and N. Rosenheimer, "Dogfish lactate dehydrogenase. The stereochemistry of hydrogen transfer," FEBS Letters, vol. 34, no. 2, pp. 143-144, 1973.

[6] C. L. Markert and F. Moller, "Multiple forms of enzymes: tissue, ontogenetic, and species specific patterns," Proceedings of the National Academy of Sciences, vol. 45, no. 5, pp. 753-763, 1959.

[7] B. Prochazka and E. D. Wachsmuth, "Isozyme patterns of lactate dehydrogenase, creatine phosphokinase, phosphoglucomutase and aldolase guinea pig tissues during ontogeny," Journal of Experimental Zoology, vol. 182, no. 2, pp. 201-210, 1972.

[8] R. S. Holmes, "Evolution of lactate dehydrogenase genes," FEBS Letters, vol. 28, no. 1, pp. 51-55, 1972.

[9] R. Richterich, E. Gautier, W. Egli, K. Zuppinger, and E. Rossi, "Progressive muskeldystrophie," Klinische Wochenschrift, vol. 39, no. 7, pp. 346-352, 1961.

[10] M. Yoshida, K. Ishikawa, and M. Kitamura, "Studies on lactate dehydrogenase isozymes of body fluids (I), an improved method of agar-gel electrophoresis on microscope slides," Seibutsu-Butsuri-Kagaku, vol. 11, pp. 69-74, 1966.

[11] T. Imai, K. Mochizuki, Y. Nishiguchi, S. Naito, and M. Yoshida, "Purification and amino acid sequence of L-lactate dehydrogenase from the skeletal muscle of the hagfish, Eptatretus okinoseanus," Journal of Analytical Bio Science, vol. 20, pp. 341348, 1997.

[12] T. Imai, Y. Nishiguchi, S. Naito, and M. Yoshida, "Purification and some properties of skeletal muscle lactate dehydrogenase from the Japanese hagfish, Myxine garmani," Journal of Analytical Bio Science, vol. 20, pp. 307-314, 1997.

[13] Y. Nishiguchi, "Evolutionary implications of lactate dehydrogenases (LDHs) of hagfishes compared to lampreys: $\mathrm{LDH}$ cDNA sequences from Eptatretus burgeri, Paramyxine atami and Eptatretus okinoseanus," Zoological Science, vol. 25, no. 5, pp. 475-479, 2008.

[14] Y. Nishiguchi, T. Miwa, and F. Abe, "Pressure-adaptive differences in lactate dehydrogenases of three hagfishes: Eptatretus burgeri, Paramyxine atami and Eptatretus okinoseanus," Extremophiles, vol. 12, no. 3, pp. 477-480, 2008. 
[15] Y. Nishiguchi and M. Okada, "Evolution of hagfish and human lactate dehydrogenases: a new view of human disease," Journal of Medical Biochemistry, vol. 153, pp. 552-556, 2009.

[16] G. C. Johns and G. N. Somero, "Evolutionary convergence in adaptation of proteins to temperature: $\mathrm{A}_{4}$-lactate dehydrogenases of pacific damselfishes (Chromis spp.)," Molecular Biology and Evolution, vol. 21, no. 2, pp. 314-320, 2004.

[17] A. A. Brindley, R. W. Pickersgill, J. C. Partridge, D. J. Dunstan, D. M. Hunt, and M. J. Warren, "Enzyme sequence and its relationship to hyperbaric stability of artificial and natural fish lactate dehydrogenases," Plos One, vol. 3, no. 4, Article ID e2042, 2008.

[18] Y. Nishiguchi, N. Ito, and M. Okada, "Structure and function of lactate dehydrogenase from hagfish," Marine Drugs, vol. 8, no. 3, pp. 594-607, 2010.

[19] Y. Nishiguchi, F. Abe, and M. Okada, "Different pressure resistance of lactate dehydrogenases from hagfish is dependent on habitat depth and caused by tetrameric structure dissociation," Marine Biotechnology, vol. 12, pp. 1-7, 2010.

[20] H. Jiang, H. Yan, W. Xuan, D. Wuying, Y. Xinbing, and H. Xuchu, "Identification, expression, characterization, and immunolocalization of lactate dehydrogenase from Taenia asiatica," Parasitology Research, vol. 104, no. 2, pp. 287-293, 2009.

[21] H. A. Wyckoff, J. Chow, T. R. Whitehead, and M. A. Cotta, "Cloning, sequence, and expression of the L-(+) lactate dehydrogenase of Streptococcus bovis," Current Microbiology, vol. 34, no. 6, pp. 367-373, 1997.

[22] U. E. Loening, "The fractionation of high-molecular-weight ribonucleic acid by polyacrylamide-gel electrophoresis," Biochemical Journal, vol. 102, no. 1, pp. 251-257, 1967. 

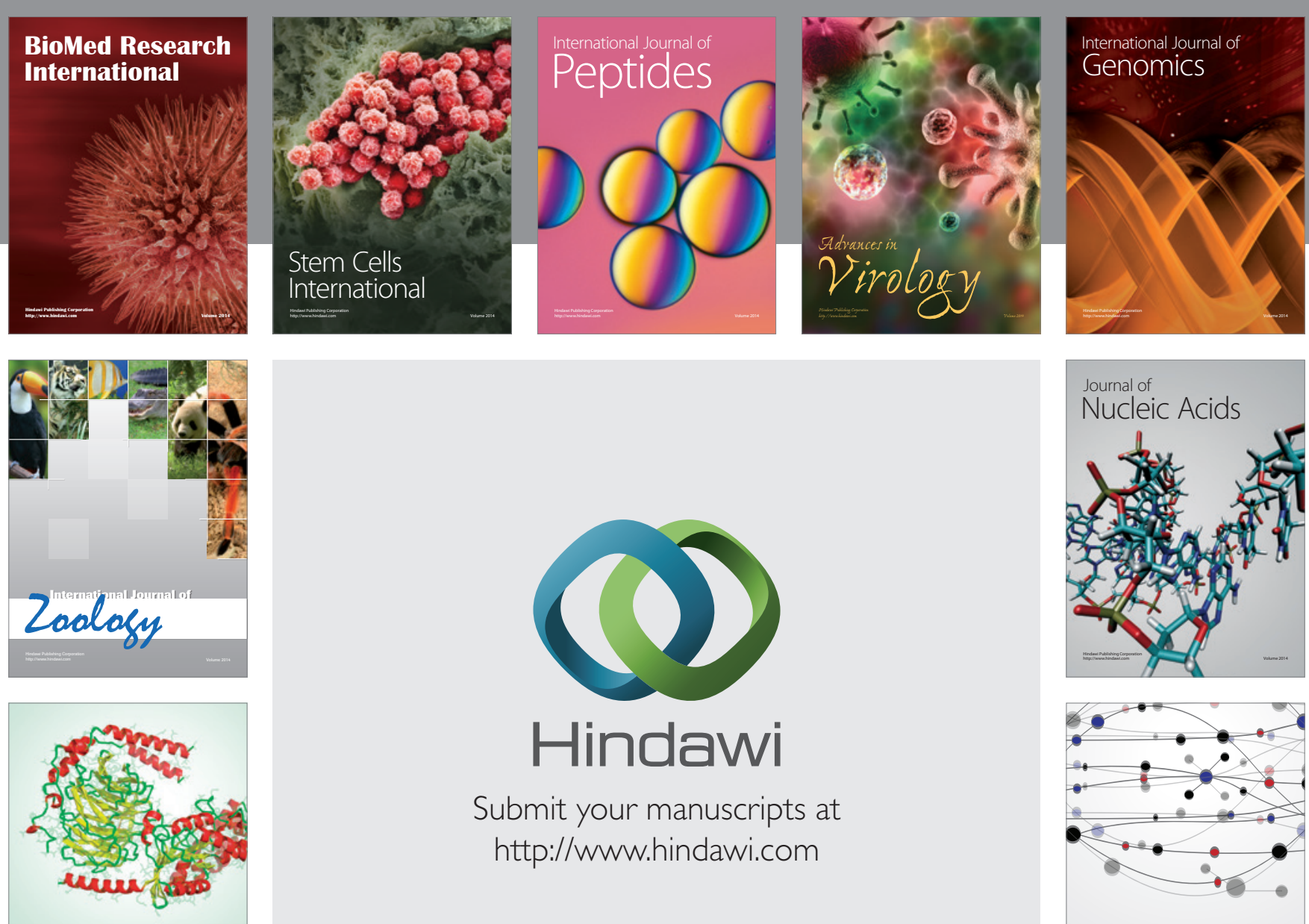

Submit your manuscripts at

http://www.hindawi.com

Signal ${ }^{\text {Jumal }}$ Transduction
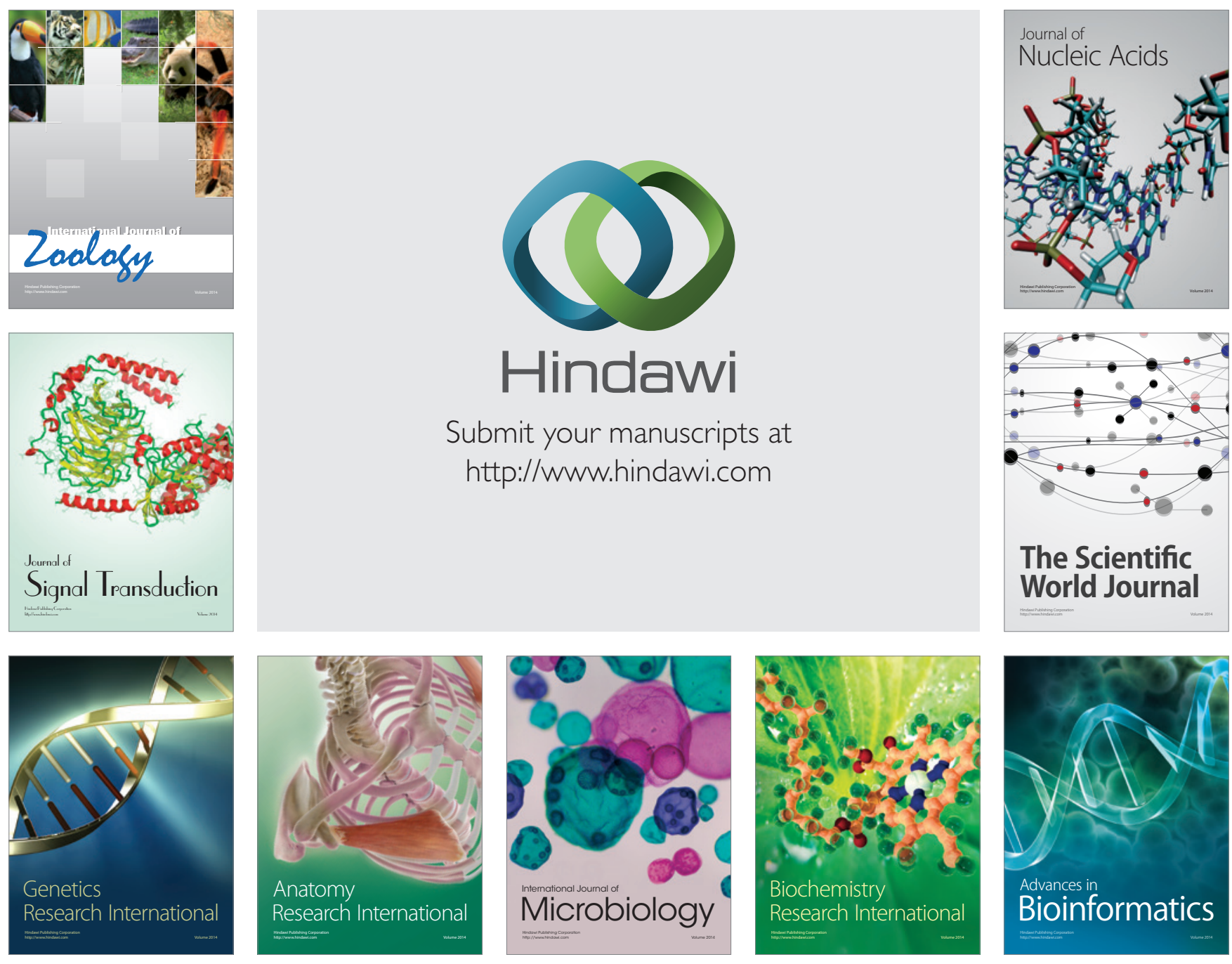

The Scientific World Journal
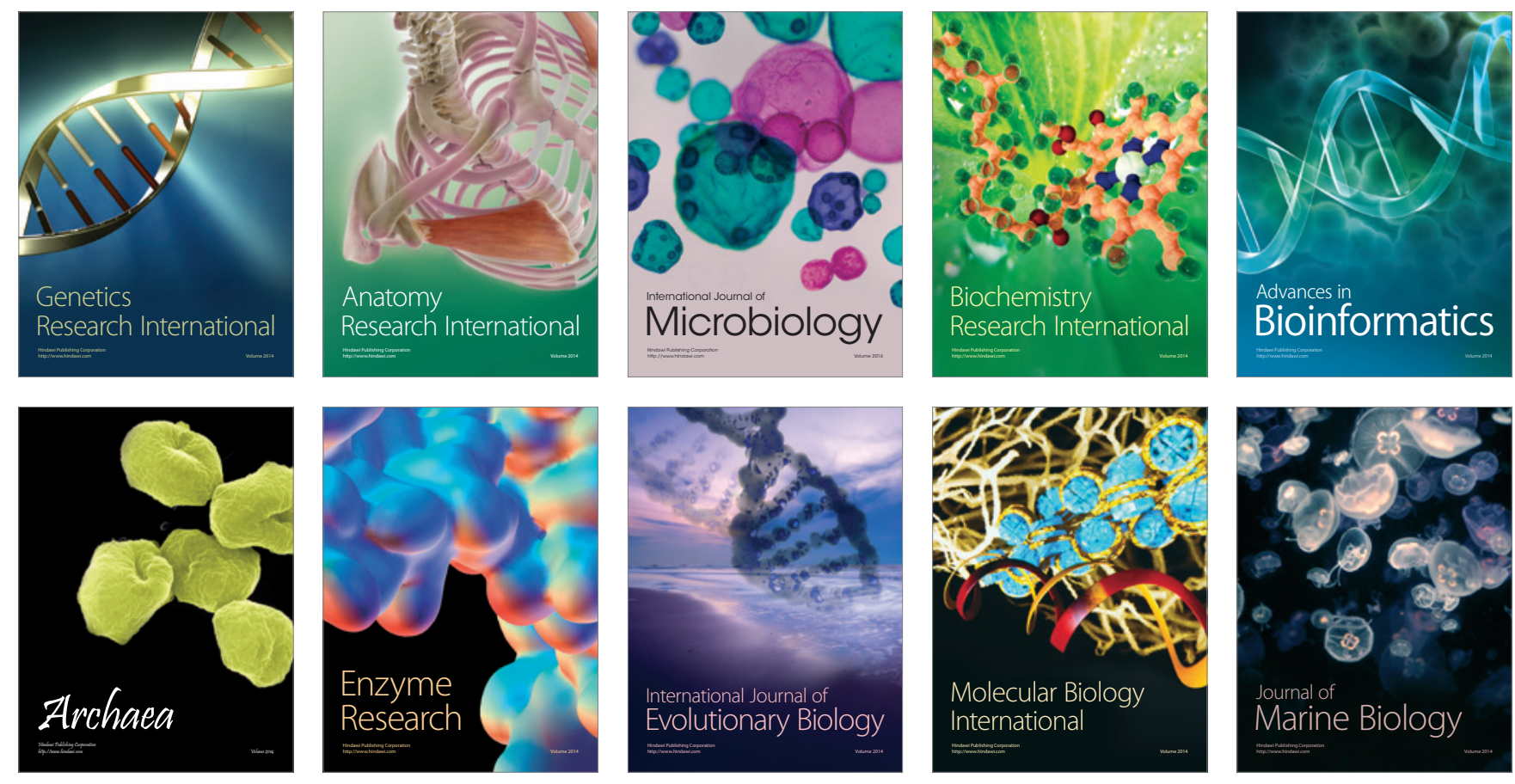